\title{
Moderate lameness leads to marked behavioral changes in dairy cows
}

\author{
H. C. Weigele, ${ }^{* 1}$ L. Gygax, ${ }^{2}$ A. Steiner, $†$ B. Wechsler, ${ }^{*}$ and J.-B. Burla* \\ ${ }^{*}$ Centre for Proper Housing of Ruminants and Pigs, Federal Food Safety and Veterinary Office (FSVO), Agroscope Tänikon, Ettenhausen 8356 , \\ Switzerland \\ †Clinic for Ruminants, Vetsuisse-Faculty, University of Bern, Bern 3012, Switzerland
}

\section{ABSTRACT}

Lameness is one of the most prevalent diseases affecting the welfare of cows in modern dairy production. Lameness leads to behavioral changes in severely lame cows, which have been investigated in much detail. For early detection of lameness, knowledge of the effects of moderate lameness on cow behavior is crucial. Therefore, the behavior of nonlame and moderately lame cows was compared on 17 Swiss dairy farms. On each farm, 5 to 11 nonlame (locomotion score 1 of 5 ) and 2 to 7 moderately lame (locomotion score 3 of 5 ) cows were selected for data collection in two 48-h periods (A, B) separated by an interval of 6 to $10 \mathrm{wk}$. Based on visual locomotion scoring, 142 nonlame and 66 moderately lame cows were examined in period $\mathrm{A}$ and 128 nonlame and 53 moderately lame cows in period B. Between these 2 periods, the cows underwent corrective hoof trimming. Lying behavior, locomotor activity, and neck activity were recorded by accelerometers (MSR145 data logger, MSR Electronics GmbH, Seuzach, Switzerland), and feeding and rumination behaviors by noseband sensors (RumiWatch halter, ITIN + HOCH GmbH, Liestal, Switzerland). Furthermore, visits to the brush and the concentrate feeder, and the milking order position were recorded. In comparison with nonlame cows, moderately lame cows had a longer lying duration, a longer average lying bout duration, and a greater lateral asymmetry in lying duration. Average locomotor activity, locomotor activity during $1 \mathrm{~h}$ after feed delivery or push-ups, and average neck activity were lower in moderately lame cows. Eating time and the number of eating chews (jaw movements) were reduced in moderately lame compared with nonlame cows, whereas no effect of moderate lameness was evident for ruminating time, number of ruminating chews and boluses, and average number of ruminating chews per bolus. Mod-

\footnotetext{
Received May 5, 2017.

Accepted November 8, 2017.

${ }^{1}$ Corresponding author: heide@weigele-hof.de

${ }^{2}$ Current address: Faculty of Life Sciences, Albrecht Daniel ThaerInstitute of Agricultural and Horticultural Sciences, HumboldtUniversität zu Berlin, 10115 Berlin, Germany.
}

erately lame cows visited the concentrate feeder and the brush less frequently, and they were further back in the milking order compared with nonlame cows. In conclusion, nonlame and moderately lame cows differed in a biologically relevant way in many of the behavioral variables investigated in this study. Therefore, the use of these behavioral changes seems to be promising to develop a tool for early lameness detection.

Key words: dairy cow, lameness, early detection, behavior, automatic recording

\section{INTRODUCTION}

Lameness is widespread in dairy cows kept in loose housing systems and represents one of the 3 major causes for early culling (Juarez et al., 2003). Over 90\% of all lameness cases are caused by claw disorders (Phillips, 2002), which result from multifactorial risk factors. Potential risks can arise from the husbandry system (e.g., type of cubicles, flooring), management (e.g., permanent indoor housing), and individual genetics (Barker et al., 2010), but also barn hygiene (i.e., bacterial infections), inadequate feeding, and insufficient or poor hoof care (Becker et al., 2014b). A high prevalence of lameness on the dairy cow level was found on farms in England and Wales (36.8\%; Barker et al., 2010) and in the northeastern United States (54.8\%; von Keyserlingk et al., 2012). In Switzerland, Becker et al. (2014a) reported a lameness prevalence of $14.8 \%$ on the cow level and $80.8 \%$ on the farm level (i.e., at least one lame cow per farm).

Lameness has a negative effect on the economic viability of farms because it results in reduced productivity (Green et al., 2002) and reproductive performance (Sogstad et al., 2006). Moreover, lameness has severe negative consequences for animal welfare (Whay et al., 2003). Therefore, early detection of lameness is of utmost importance. It allows early intervention and contributes to the prevention of more severe claw disorders, which cause almost 3 times higher costs than mild claw disorders (Charfeddine and Pérez-Cabal, 2017).

To be applicable on farms, a reliable method for the detection of lameness is essential. The most direct meth- 
od is visual gait analysis (locomotion scoring; Sprecher et al., 1997). Changes in limb movements occur due to the pain that is associated with claw disorders (Dyer et al., 2007). In multiple studies, however, it has become evident that the reliable detection of lameness by farmers is difficult. In this respect, various attempts have been made to use technical equipment for gait analysis and develop detection systems that automatically warn farmers about lameness incidences. Currently, 2 types of systems are in use on farms (Rutten et al., 2013; Nechanitzky et al., 2016; Jabbar et al., 2017): permanently installed in the housing environment (e.g., weighing platforms, video analysis, 3-dimensional cameras) or cow-attached systems (e.g., pedometer). However, according to Rutten et al. (2013), the current systems are mainly able to detect severe lameness, which can also easily be identified visually.

Besides changes in gait, lameness leads to other changes in cow behavior. In lame dairy cows, recent studies found, for example, reduced locomotor activity (Thorup et al., 2015), longer lying duration (Solano et al., 2016), and reduced usage of an automated grooming brush (Mandel et al., 2018) as compared with nonlame cows. However, most studies grouped cows of different lameness scores, whereas less is known about lamenessinduced behavioral changes in moderately lame cows specifically.

The aim of this study was to identify behavioral variables that have the potential to be used as indicators for automatic early lameness detection. Therefore, the behavior of nonlame and moderately lame cows was compared on 17 Swiss dairy farms during 2 data collection periods of 48-h each, separated by an interval of 6 to 10 wk. Lying behavior, locomotor and neck activity, feeding and rumination behaviors, brush and concentrate feeder visits, and the milking order were examined in the same cows in both periods. It was hypothesized that the behavior of moderately lame cows would be affected in a similar direction as has been described for severely lame cows but to a smaller extent. In addition, we analyzed the lateral asymmetry in lying behavior and locomotor activity of cows during $1 \mathrm{~h}$ after feed delivery or push-ups, behavioral patterns that, to the best of our knowledge, have rarely been investigated as indicators of lameness.

\section{MATERIALS AND METHODS}

\section{Farms and Cows}

Ethical approval for the study was obtained from the Veterinary Office of the Canton Zurich (Switzerland; ZH061/15, approval no. 26475). Data were collected between October 2015 and March 2016. The study was conducted on 17 dairy farms in Switzerland. Farmers were informed about the study by personal inquiry or public advertisement (online homepages of breeding associations and a print magazine). Farms were qualified for participation in the study if their loose housing systems provided an indoor area with cubicles (15 farms had cubicles with deep bedding, 2 farms with rubber mats and thin bedding; $\geq 1$ cubicle per cow) and a permanently accessible outdoor area. Cows were milked in a milking parlor twice daily. Roughage was provided ad libitum at a feed fence (with head lock; $\geq 1$ feeding place per cow), and concentrate was offered in automatic feeders (except on one farm, where no concentrate feeder was available). At least one automatically rotating brush was available for the cows. Farm management remained unchanged for the study; however, no access to pasture was granted to the cows from at least $3 \mathrm{~d}$ before and during data collection.

Herd size ranged from 31 to 91 (mean \pm SD: $55.9 \pm$ 17.4) lactating cows. Based on visual locomotion scoring, the prevalence of lameness in the herds ranged from 9.4 to $72.3 \%$ (mean \pm SD: $29.8 \pm 15.7 \%$ ). In each herd, samples of 5 to 11 nonlame and 2 to 7 moderately lame lactating cows were selected as focal cows. Cows were included in the study if they had no apparent disease or veterinary treatment during the 4 wk before data collection and a lactation stage of more than 14 DIM at the beginning of data collection. Furthermore, the most recent corrective hoof trimming had to have taken place at least 2 wk before data collection. Focal cows were aged from 2 to $15 \mathrm{yr}$ (mean $\pm \mathrm{SD}: 5.9 \pm 2.7$ ), were between their first and twelfth lactation (mean \pm SD: $3.7 \pm 2.3$ ), ranged from 14 to 694 DIM (mean \pm SD: $174 \pm 110.8)$, and belonged to the breeds Brown-Swiss $(\mathrm{n}=79)$, Fleckvieh $(\mathrm{n}=22)$, Holstein-Friesian $(\mathrm{n}=$ $75)$, and Red Holstein $(\mathrm{n}=57)$. The majority of the focal cows were between their third and sixth lactation (64\% nonlame, $61 \%$ moderately lame) and between 55 and 265 DIM (62\% nonlame, $60 \%$ moderately lame).

\section{Experimental Design and Visual Locomotion Scoring}

On each farm, data were collected during 2 identical 48-h periods (A, B) separated by an interval of 6 to 10 wk. Between the 2 periods, but at least 2 wk before pe$\operatorname{riod} \mathrm{B}$, corrective hoof trimming was performed either by the farmer or by a professional hoof trimmer. Including the pre- and postrecording times, each period lasted $4 \mathrm{~d}$. On d 1 of period A, a preliminary visual locomotion scoring was conducted on the entire dairy herd to select the focal cows. The selected cows were fixed in the head lock of the feed fence to attach the measuring devices 
and for individual marking with animal marking spray (Raidex, Arndt Europadiscount, Hochdorf, Germany). Focal cows were marked with numbers sprayed on each side of their shoulder and croup for individual recognition. According to their infrared reflecting properties at night, different spray colors were used on different coat colors. Habituation to wearing the measuring devices lasted until midnight of d $1(\geq 12 \mathrm{~h}$; Braun et al., 2015), when data recording started. On d 2 and 3, data were recorded continuously for a total of $48 \mathrm{~h}$. If medical treatment was necessary during data collection periods, cows were excluded from the study. When focal cows were released individually from the head lock, a comprehensive locomotion scoring was performed by 2 observers based on Sprecher et al. (1997). Thereby, all scoring sequences were video recorded to allow for a retrospective reassessment. Sprecher's locomotion scoring system is based on an ordinal scale from 1 to 5 including gait and back posture during walking and standing for the assessment. A locomotion score of 1 was defined as nonlame and a locomotion score of 3 as moderately lame; cows with locomotion scores 2, 4, and 5 were not considered in the study. Standing and walking were assessed in all cows individually on planar floors (on 3 of the 17 farms, planar floors were additionally covered with rubber mats). To ensure that a cow's locomotion score did not change within a period (A or $\mathrm{B})$, the locomotion scoring was repeated at the end of each period (d 4).

Both observers (an experienced behavioral researcher and a veterinarian) were trained in visual locomotion scoring by a specialized veterinarian before the study. Training sessions took place on 2 dairy farms, where locomotion scoring videos of 268 cows were taken. After an intensive training period with these videos, the training success was reviewed by the specialized veterinarian during another on-farm locomotion scoring session on a third farm and confirmed that the observers were able to correctly classify lameness scores according to Sprecher et al. (1997). At the beginning of the study, the inter-observer agreement between these 2 observers was further reviewed with 193 cows on 4 of the study farms and reached an agreement of $92.8 \pm 2.9 \%$ (mean $\pm \mathrm{SD}$ ). In case of a disagreement between the observers concerning a cow's locomotion score during the on-farm scoring, the observers reassessed the cow's score based on the video recordings. If no agreement was achieved, the cow was excluded from the statistical analysis for the respective period.

Cows were only included in the data collection of period B if their locomotion score in period B still matched 1 of the 2 scores examined in this study (either locomotion score 1 or 3 ). However, as the number of cows that changed their locomotion score from period A to period B was very small (14 cows), these individuals were excluded from the statistical analysis. Further, a change in locomotion score within a period led to the exclusion of the cow in the respective period. Overall, 219 cows were included in the study of which 66 cows were moderately lame and 142 nonlame in period A, and 53 cows were moderately lame and 128 nonlame in period $\mathrm{B}$.

\section{Data Recording and Processing}

Accelerometers. Lying behavior, locomotor activity, and neck activity were measured automatically by means of 3-dimensional accelerometers (MSR145 data logger, MSR Electronics GmbH, Seuzach, Switzerland). These accelerometers were already validated and used in previous studies for the recording of locomotor activity and lying behavior in cows (Gygax et al., 2015; Johns et al., 2015) and horses (Burla et al., 2014; Burla et al., 2017). The MSR data loggers recorded acceleration in horizontal, vertical, and lateral direction of the leg with a sampling rate of $1 \mathrm{~Hz}$ and a sensitivity of $\pm 16 \mathrm{~g}$. Via MSR software (version 5.28.14, MSR Electronics GmbH, Seuzach, Switzerland), raw data were transmitted to a computer as CSV files, and R (version 3.3.2; R Core Team, 2016) was used for the calculation of outcome variables.

Lying Behavior. To measure lying behavior, an accelerometer was attached laterally at the metatarsus of the cow's left hind leg with a Velcro strap, and a foam pad was used underneath to prevent pressure sores. Furthermore, elastic bandages and duct tape were used to prevent damage and keep the data logger clean and dry. Lying bouts were detected based on a threshold decision for every single data point. Each acceleration value of the vertical direction of the leg was categorized as lying if it was greater than $-0.5 \mathrm{~g}$ and categorized as an upright position if it was smaller than $-0.5 \mathrm{~g}$. In addition, a running median smoothed this decision across $120 \mathrm{~s}$ (60 s situated before and $60 \mathrm{~s}$ after the data point in question) to account for short-term fluctuations. Only lying bouts lasting at least $60 \mathrm{~s}$ were considered for statistical analysis. For each cow, the lying duration, number of lying bouts, and average lying bout duration were calculated per $24 \mathrm{~h}$. Furthermore, the lateral asymmetry in lying behavior was quantified. Acceleration values of the lateral direction of the leg were attributed to be lying on the right side if greater than $-0.5 \mathrm{~g}$ or lying on the left side if smaller than $-0.5 \mathrm{~g}$, and each lying bout was assigned to be on the right or left side according to the majority of attributions. Based on these assignments, the lateral asymmetry in 
the number of lying bouts was calculated by dividing the number of lying bouts on the left side by the total number of lying bouts. Similarly, the lateral asymmetry in lying duration was determined by dividing the lying duration on the left side by the total lying duration. To represent the degree of asymmetry for both variables but without specifying to which side, asymmetry ratios smaller than 0.5 were subtracted from 1 , and these values (ranging from 0.5 to 1 ) were subsequently translated to a scale from 0 to 1 . This translation resulted in asymmetry ratios between 0 (no asymmetry) and 1 (complete asymmetry) for the lateral asymmetry in the lying behavior.

Locomotor Activity. Locomotor activity was determined using data of the accelerometer attached to the hind leg. To calculate the average locomotor activity per hour, absolute differences of acceleration values of all 3 directions were summed and divided by 24 . In addition, the average locomotor activity in upright position was calculated after excluding all data points during lying. Furthermore, the locomotor activity during $1 \mathrm{~h}$ after feed delivery or push-ups was examined. However, intervals that overlapped with the period $1 \mathrm{~h}$ after milking were excluded because most cows were fixed in the head lock during this time.

Neck Activity. The activity of the cows was additionally measured by means of an accelerometer, which was attached to the lowest point of the cow's neck collar (usually next to the transponder). Due to the attachment of the measuring device on the neck collar and not the animal itself, it is less likely to cause injuries or pressure sores, where neck activity could be an advantageous alternative to locomotor activity measured by pedometers. To calculate the average neck activity per hour, absolute differences of acceleration values of all 3 directions were summed up and divided by 24 .

Noseband Sensors. For the measurement of feeding and rumination behaviors, cows were wearing a pressure sensor for chewing movement detection (RumiWatch halter, ITIN + HOCH GmbH, Liestal, Switzerland; information on the basic concept of the algorithm for the identification of eating and ruminating jaw movements is available in Zehner et al., 2017). Pressure inside an oil-filled silicone tube in the noseband of the halter was recorded with a sampling rate of $10 \mathrm{~Hz}$. Raw data were transferred to a computer and processed with the software RumiWatch Manager 2 (version 2.1.0.0, ITIN + HOCH GmbH). Raw data were converted into 1-h summaries by using the software RumiWatch Converter (version 0.7.3.36, ITIN + HOCH GmbH), and the following variables (for detailed definitions see Beer et al., 2016; validated by Zehner et al., 2017) were evaluated: ruminating time, number of ruminating chews, number of boluses, average ruminating speed, average number of ruminating chews per bolus, eating time, and number of eating chews. The average mastication speed was additionally calculated by dividing the number of eating chews by eating time. For the statistical analysis, values of a variable were added up across $24 \mathrm{~h}$, except for the variables average ruminating and mastication speed, and number of ruminating chews per bolus, for which a daily mean was calculated. Because the latest version of the RumiWatch Converter was known to be the most precise one, this version was used for the conversion of the RumiWatch data. To replace RumiWatch halters under repair, MSR halters, validated by Braun et al. (2013), were used for data collection instead. Raw data from the MSR halters were converted accordingly by using the RumiWatch Converter, although only an older version (0.6.4.0) was able to convert MSR data files. To ensure the validity of the older version, the general agreement of the 2 RumiWatch Converters (version 0.6.4.0 and version 0.7.3.36) was checked by using all RumiWatch raw data of our study. In the range of the MSR halter values, the converter agreement was calculated in R (package agreement; Yu and Lin., 2012) for 7 RumiWatch outcome variables, showing a very good agreement [median (range): 0.85 (0.75-0.99)] of the 2 RumiWatch Converter versions.

Video Recordings and Transponder Systems. Infrared video cameras were used to record the visits to automatically rotating brushes, the visits to concentrate feeders, and the milking order of the cows. To reduce the amount of video material, recordings were initiated either by motion sensors (visits to the brush and concentrate feeder) or according to a recording schedule (milking order). All video recordings were analyzed by the same observer.

Brush Visits. A visit to the brush was defined as physical contact of the cow with the brush while either the cow was scratching actively or the brush was rotating for a minimum duration of $5 \mathrm{~s}$. A visit was counted as a new visit if the cow did not interact with the brush as defined for more than $60 \mathrm{~s}$ or stepped away from the brush for more than one cow length. For the analysis, the number of visits to the brush per $24 \mathrm{~h}$ was calculated per cow.

Concentrate Feeder Visits. The number of visits to the concentrate feeder per $24 \mathrm{~h}$ was recorded per cow. A visit was counted each time the cow positioned its front legs inside the concentrate feeder station and considered as terminated when the cow had removed all feet from the concentrate feeder station. In case the on-farm transponder system was able to give the appropriate output needed for the identification of individual visits (on 2 of 16 farms), the number of visits was recorded automatically by the system. Furthermore, the amount of concentrate leftovers per 
$24 \mathrm{~h}$ was automatically recorded by the on-farm transponder systems. Concentrate leftovers were defined as the amount of concentrate that was not collected by a particular cow (and therefore was not dispersed by the concentrate feeder). If the percentage of leftovers of a cow was greater than $5 \%$ of its total daily amount of concentrate, an "incidence of leftovers" was recorded. Focal cows that did not receive any concentrate feed were excluded from this analysis.

Milking Order Index. The focal cows' position in the dairy herd's milking order was identified either from recordings of a video camera installed at the entrance or the exit of the milking parlor (on 9 of 17 farms) or automatically by the farm's milking system according to the recognition of the cows' individual transponders. The milking order index (i.e., the quotient of each focal cow's position divided by the total number of cows) was calculated for each of the 4 milking times per period. Accordingly, the milking order index ranged between 0 (= first in the herd) and 1 (= last in the herd).

\section{Statistical Analysis}

Statistical analyses were carried out in $\mathrm{R}$ (version 3.3.2; R Core Team, 2016) using linear mixed-effects models and generalized linear mixed-effects models (lmer and glmer; package lme4; Bates et al., 2015). An overview of all analyzed outcome variables is given in Table 1. Model assumptions were checked by graphical analysis of residuals; outcome variables were transformed if necessary (Table 1). Locomotion score (factor with 2 levels: nonlame, moderately lame) was included in the model as fixed effect. Furthermore, DIM and parity operated as nuisance factors in the models. To account for repeated measurement within $(2 \times 48 \mathrm{~h})$ and between periods, the random effect contained the day (only in case of the milking order index) nested in the period (A, B) nested in the individual cow nested in the farm. In addition, a crossed random effect with an identification of each day in each period on each farm was included to account for the fact that the focal animals on a given farm were observed simultaneously (and, therefore, might have been equally affected by any extraordinary event on a farm on a given day). The $P$-values were calculated using parametric bootstrap (PBmodcomp; package pbkrtest; Halekoh and Højsgaard, 2014) by comparing the statistical models with and without the fixed effect locomotion score. For the bootstrap, the number of 1,000 samples was chosen. Therefore, a $P$-value of 0.001 is the lowest value that could result from this method, although the actual $P_{-}$ value might have been even lower. Model estimates and 95\% confidence intervals of the fixed effect locomotion score were calculated for outcome variables with a $P$ - value $<0.1$ for that score, wherein the nuisance factors were set to their median of the respective data sample.

Some data points had to be excluded from the analysis (see Table 1 for number of nonlame and moderately lame cows in period A and B for each outcome variable) for one of the following reasons: technical issues, cow in heat, cow no longer lactating in period $\mathrm{B}(\mathrm{n}=$ 5 ), removal of the cow before the start of period B (n $=7$ ), or identification as outliers $(\mathrm{n}=15 ;<2 \%$ of the sample size per outcome variable).

\section{RESULTS}

Moderately lame cows had a longer lying duration (Figure 1A; Table 1) but a similar number of lying bouts (Figure 1B; Table 1) than nonlame cows. This resulted in a longer average lying bout duration in moderately lame cows [model estimate (95\% CI): 89.88 min $(84.76,95.85)$; Table 1] compared with nonlame cows $[81.86$ min $(78.54,85.08)$; Table 1]. The lateral asymmetry in the lying duration (Figure 1C; Table 1) was greater and the lateral asymmetry in the number of lying bouts was tendentially higher in moderately lame cows $[0.17(0.14,0.23)$; Table 1$]$ than in nonlame cows [0.13 (0.11, 0.16); Table 1].

The average locomotor activity (Figure 2A; Table 1) and the locomotor activity during $1 \mathrm{~h}$ after feed delivery or push-ups (Figure 2B; Table 1) were lower in moderately lame cows than in nonlame cows, whereas no difference was found concerning the average locomotor activity in upright position (mean \pm SD: 422.6 $\pm 91.38 \mathrm{~g} / \mathrm{h}$; Table 1 ). Further, moderately lame cows also showed a lower average neck activity than nonlame cows (Figure 2C; Table 1).

Eating time (Figure 3A; Table 1) was shorter in moderately lame than in nonlame cows. Likewise, the number of eating chews per $24 \mathrm{~h}$ was lower in moderately lame cows compared with nonlame cows (Figure 3B; Table 1). The average mastication speed did not differ between moderately lame and nonlame cows (mean \pm SD: $69.75 \pm 7.08$ eating chews per eating time; Table 1). Also, no effect of moderate lameness was evident in ruminating time (Figure $3 \mathrm{C}$; Table 1), number of ruminating chews (mean \pm SD: 31,368 \pm 6,884 no. $/ 24 \mathrm{~h}$; Table 1), number of boluses (mean \pm SD: $531.0 \pm 93.19$ no. $/ 24$ h; Table 1 ), average ruminating speed (mean \pm SD: $68.28 \pm 5.92$ ruminating chews per ruminating time; Table 1 ), and the average number of ruminating chews per bolus (mean \pm SD: $58.79 \pm$ 6.75 no./bolus; Table 1 ).

The number of visits to the brush was lower in moderately lame cows compared with nonlame cows (Figure 4A; Table 1). Moderately lame cows also visited the 
BEHAVIORAL CHANGES IN MODERATELY LAME COWS

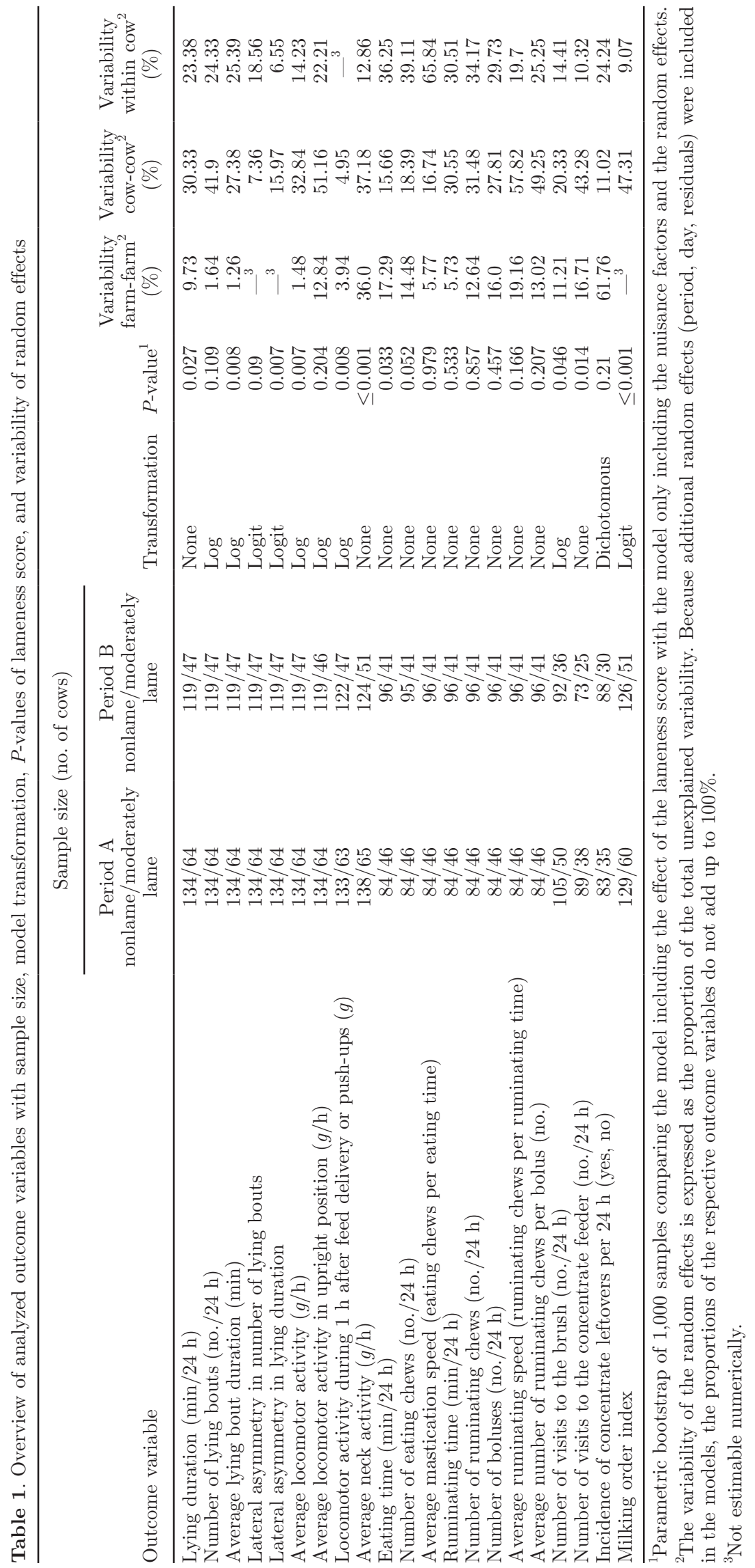


A

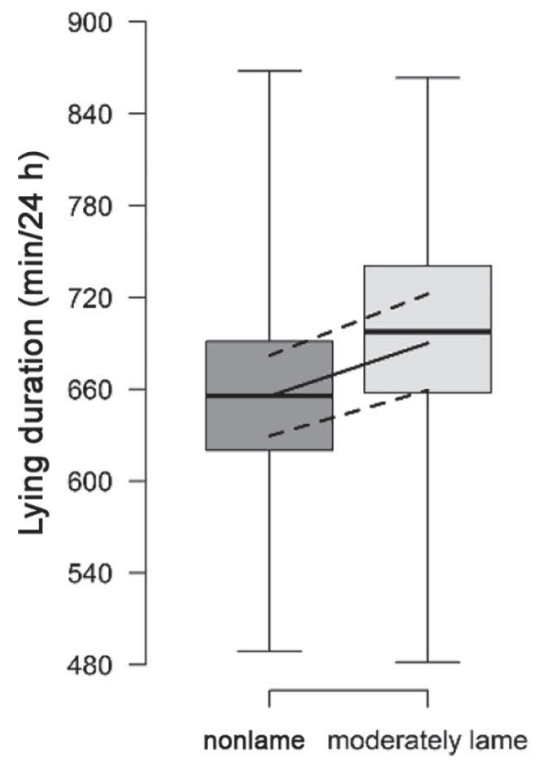

B

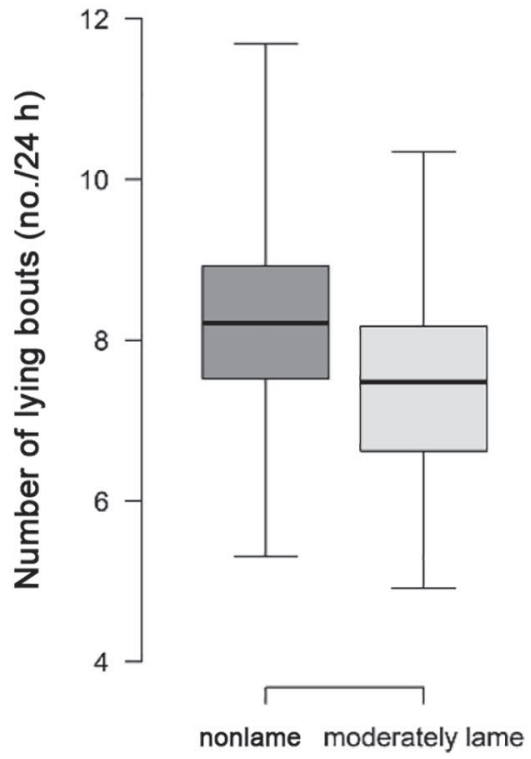

C

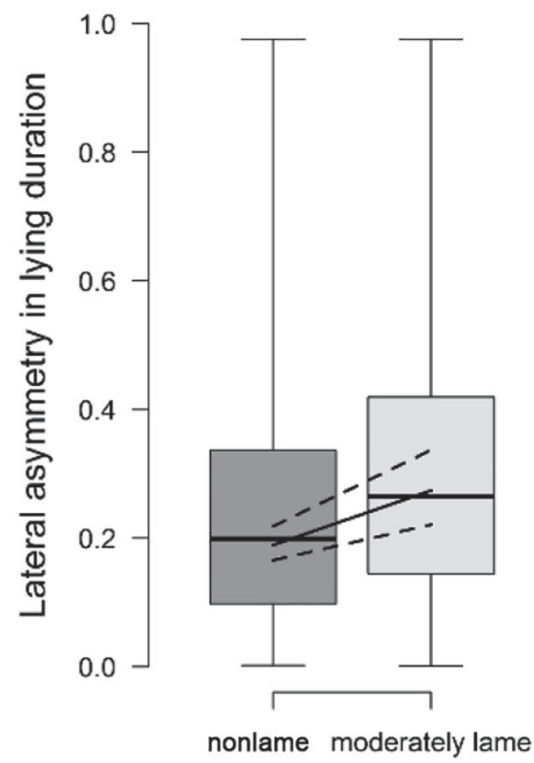

Figure 1. Lying duration (A), number of lying bouts (B), and lateral asymmetry in lying duration (C) in nonlame and moderately lame cows. Box plots in the figure represent model predictions plus residuals corresponding to the raw data minus the random effects. Medians (horizontal line), interquartile ranges (box), and absolute ranges (whiskers) are shown in addition to model estimates (solid line) with 95\% CI (dashed lines).

concentrate feeder less frequently than nonlame cows (Figure 4B; Table 1). In contrast, moderately lame and nonlame cows showed a similar probability for an incidence of concentrate leftovers (mean \pm SD: $0.22 \pm$
0.05; Table 1). Furthermore, moderately lame cows had a higher milking order index, indicating that they were further back in the milking order than nonlame cows (Figure 4C; Table 1).
A

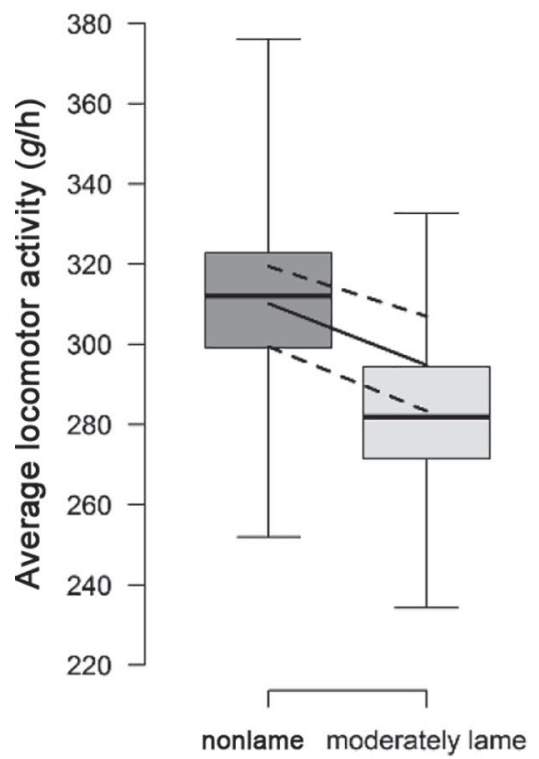

B

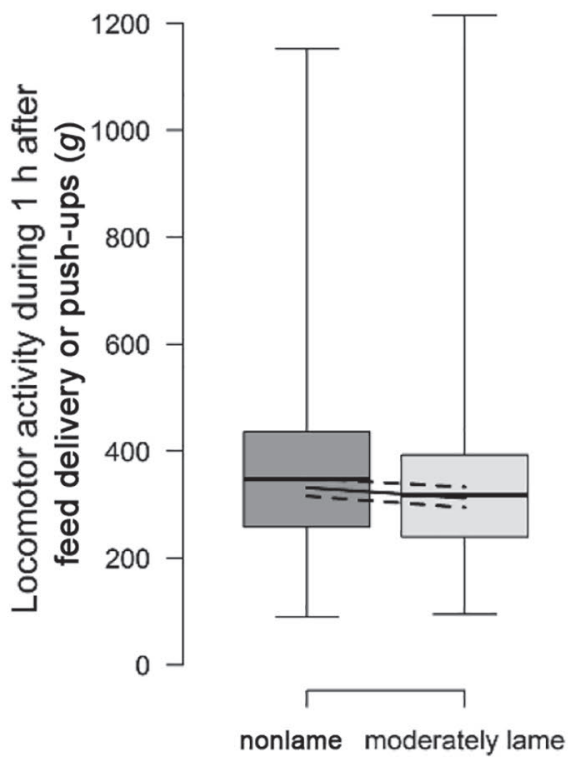

C

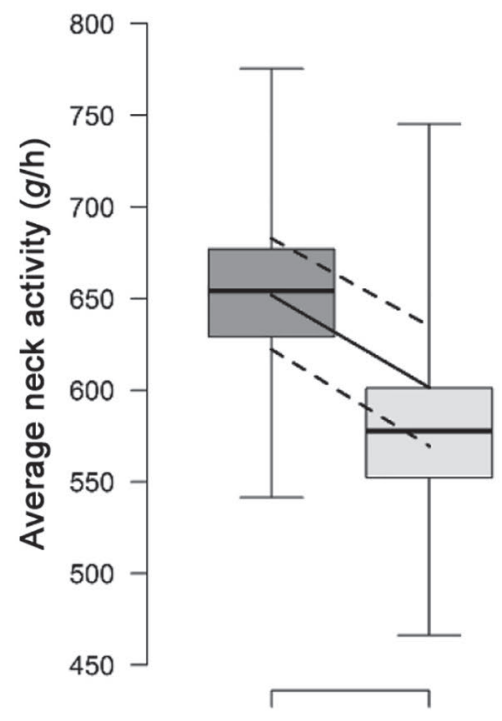

nonlame moderately lame

Figure 2. Average locomotor activity (A), locomotor activity during $1 \mathrm{~h}$ after feed delivery or push-ups (B), and average neck activity (C) in nonlame and moderately lame cows. Box plots in the figure represent model predictions plus residuals corresponding to the raw data minus the random effects. Medians (horizontal line), interquartile ranges (box), and absolute ranges (whiskers) are shown in addition to model estimates (solid line) with 95\% CI (dashed lines). 
A

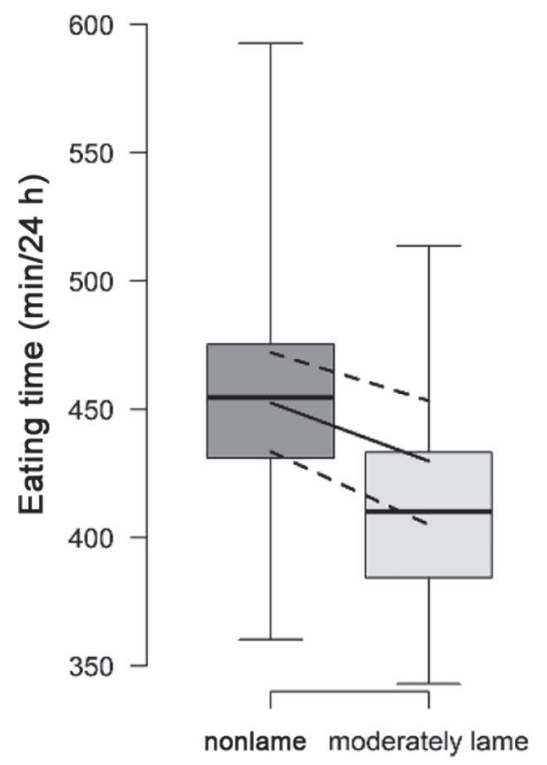

B

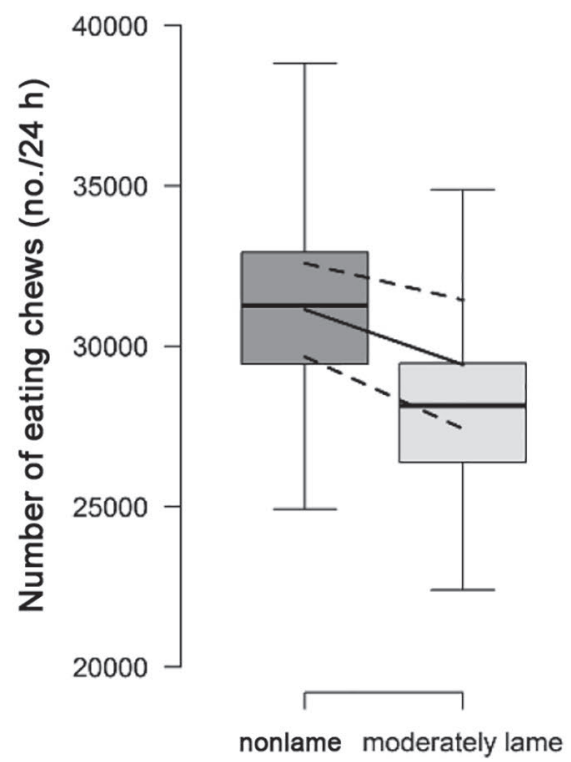

C

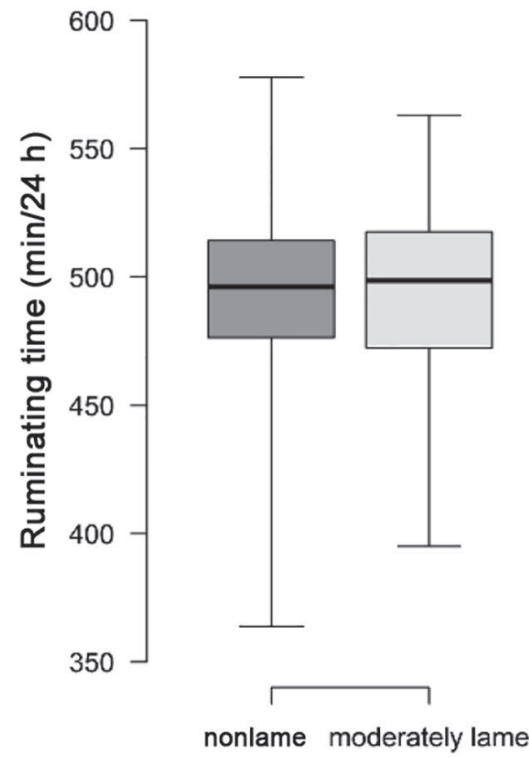

Figure 3. Eating time (A), number of eating chews (B), and ruminating time (C) in nonlame and moderately lame cows. Box plots in the figure represent model predictions plus residuals corresponding to the raw data minus the random effects. Medians (horizontal line), interquartile ranges (box), and absolute ranges (whiskers) are shown in addition to model estimates (solid line) with 95\% CI (dashed lines).

In general, farm-to-farm variability was lower than cow-to-cow variability (Table 1 ). Within-cow variability was also lower than cow-to-cow variability in most of the outcome variables (Table 1).

\section{DISCUSSION}

Moderate lameness influenced lying-, activity-, and eating behaviors and the milking order in lactating
A

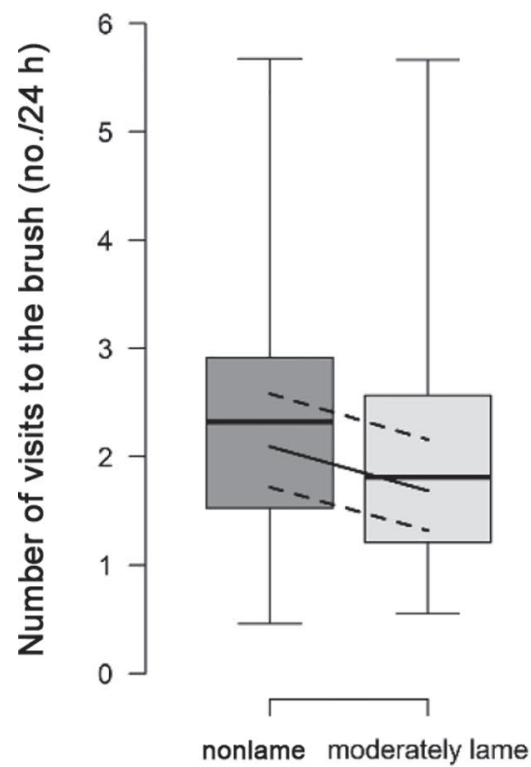

B

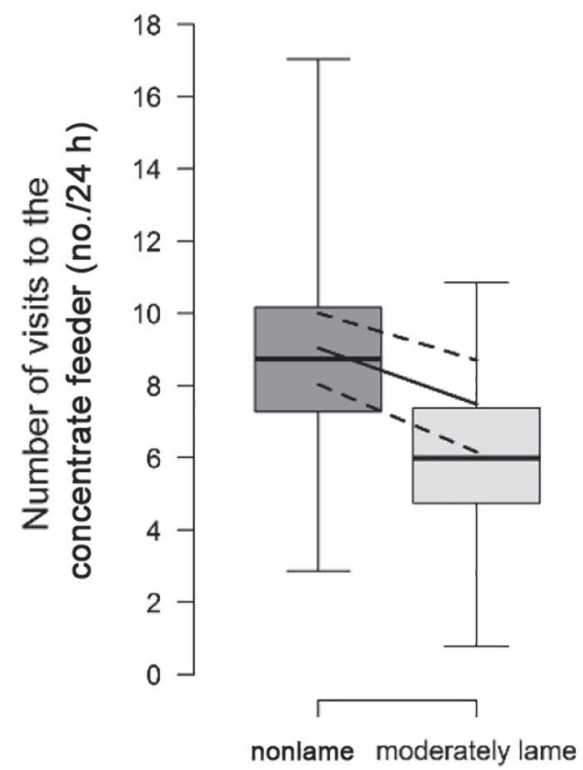

C

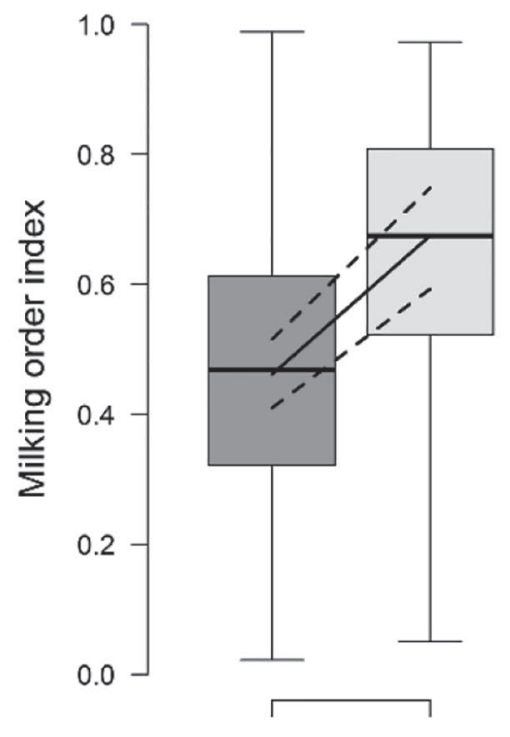

nonlame moderately lame

Figure 4. Number of visits to the brush (A), number of visits to the concentrate feeder (B), and milking order index (C) in nonlame and moderately lame cows. Box plots in the figure represent model predictions plus residuals corresponding to the raw data minus the random effects. Medians (horizontal line), interquartile ranges (box), and absolute ranges (whiskers) are shown in addition to model estimates (solid line) with $95 \%$ CI (dashed lines). 
dairy cows. However, no or little effect of moderate lameness was found on several rumination variables and on the probability of concentrate leftovers.

Moderately lame cows showed an approximately 45-min increase in daily lying duration in comparison with nonlame cows. The lying duration of the nonlame cows in our study was similar to durations measured in other studies with loose housing (von Keyserlingk et al., 2012; Deming et al., 2013) and other housing systems (Tucker et al., 2004). A comparable effect of lameness on lying duration has been observed in cows with different lameness scores $(\geq 3$ of 5$)$, for which an increase in daily lying duration of 36 to 120 min was found (Ito et al., 2010; Blackie et al., 2011b; Thorup et al., 2015). The daily lying duration of moderately lame cows in the present study ranged between that of nonlame and previously observed severely lame cows, which indicates a positive relationship between lying duration and the degree of lameness. The number of lying bouts in nonlame cows was similar to findings in other studies (Sepulveda-Varas et al., 2014; Solano et al., 2016). The number of lying bouts did not differ between moderately lame and nonlame cows in the present study. This finding is in line with other studies (Chapinal et al., 2010; Ito et al., 2010; Blackie et al., 2011b), whereas Thomsen et al. (2012) and SepulvedaVaras et al. (2014) found a lower number of lying bouts in moderately lame and severely lame cows compared with nonlame cows. The longer lying duration in combination with a similar number of lying bouts in moderately lame cows in our study resulted in a longer average lying bout duration in comparison with nonlame cows. Our findings are supported by several studies in cows with lameness of different severity (Ito et al., 2010; Alsaaod et al., 2012; Sepulveda-Varas et al., 2014). The changes in lying behavior can be attributed to the fact that lame cows spend less time elevated on their feet (Walker et al., 2008), which possibly is a strategy to avoid weight bearing on affected limbs (Juarez et al., 2003). With regard to lateral asymmetry in lying behavior, we found that compared with nonlame cows, moderately lame cows showed more lateral asymmetry in lying duration and tended to have more lateral asymmetry in the number of lying bouts. Because we did not assign lameness to a specific limb, we cannot state whether the cows preferred to place an affected limb in the upper or lower position. Although lateral asymmetry in lying behavior has rarely been investigated with respect to lameness, 2 possible hypotheses may apply. On the one hand, the affected leg might preferably be placed in the upper position because this limb can be moved more freely (Kokin et al., 2014) and is less exposed to weight pressure. On the other hand, the affected leg might preferably be placed in the lower position because the weight resting on this leg may influence blood circulation, causing numbness in this leg and subsequently leading to pain reduction (Dee Whittier, 2008).

The lower average locomotor activity in moderately lame cows compared with nonlame cows can probably be explained by the reduced time of being elevated on their feet (Walker et al., 2008) and agrees with observations in cows with lameness of different severity (O'Callaghan et al., 2003; Thorup et al., 2015). This reduction in activity was the result of longer lying durations, as the locomotor activity in upright position (lying bouts excluded) did not differ between moderately lame and nonlame cows. Furthermore, the locomotor activity during $1 \mathrm{~h}$ after feed delivery or push-ups was lower in moderately lame than nonlame cows. This result suggests that nonlame cows react more quickly to feed delivery or push-ups (Blackie et al., 2011a) and, therefore, supports our hypothesis that lame cows are less willing to get up and walk to the feed alley for freshly delivered feed. In addition, we would have expected an even greater difference in the locomotor activity during $1 \mathrm{~h}$ after milking as Juarez et al. (2003) found that the percentage of cows lying down after their return from the milking parlor increased with increasing severity of lameness. This presumably occurs due to the increased pain of weight bearing (while waiting for and during milking) with increasing severity of lameness. However, this variable could not be analyzed because most of the farms fixed their cows in the head locks for up to $1.5 \mathrm{~h}$ after milking. The average neck activity was lower in moderately lame compared with nonlame cows. In line with this result, Van Hertem et al. (2013) found a higher night-to-day ratio of neck activity in lame than in nonlame cows. In comparison with locomotor activity measurements using devices attached to a leg, neck activity does not provide detailed information on lying, standing, and walking. However, neck activity could be used more feasible for lameness detection on commercial farms because the device can be attached easily to the collar band and is less likely to cause injuries or pressure sores (Nielsen et al., 2010; Kokin et al., 2014) compared with pedometers, specifically during permanent on-farm use. Neck activity measurements are already in use for estrus detection in cows (Lovendahl and Chagunda, 2010; Aungier et al., 2012; Roelofs et al., 2017).

The values of our measurements of eating and rumination behaviors in nonlame cows generally agreed with those found in earlier studies (Beer et al., 2016; Leiber et al., 2016). Eating time and the number of eating chews were reduced in moderately lame cows, which was also found by Beer et al. (2016). In accordance with Palmer et al. (2012), we suggest that lame 
cows spent less time eating to reduce the duration of standing on painful limbs or feet. Bareille et al. (2003) found that lame cows have a lower total feed intake than nonlame cows, which may be connected with a poorer BCS in lame cows (Walker et al., 2008; Bicalho et al., 2009). On the other hand, several studies measured a higher feeding rate (feed intake per min) in lame cows and thus concluded that they eat faster than nonlame cows (González et al., 2008; Norring et al., 2014; Thorup et al., 2016). In the present study, however, moderately lame and nonlame cows did not differ in average mastication speed (eating chews divided by eating time). Taking these results (reduced eating time and number of eating chews, no difference in average mastication speed) into account, we can assume that moderately lame cows in our study potentially had a poorer comminution of feed. The ruminating time, number of ruminating chews, number of boluses, and average ruminating speed, however, were not affected by moderate lameness. Although cows can ruminate during standing, the greater part of rumination occurs during lying (Kilgour, 2012; Schirmann et al., 2012), whereas eating is performed while standing. Therefore, the effect of lameness on rumination might be smaller than its effect on eating. This notion is supported by Thorup et al. (2016), who also found reduced eating behavior but similar rumination behavior in lame cows compared with nonlame cows.

The number of visits to the brush was lower in moderately lame compared with nonlame cows. Mandel et al. (2018) hypothesized that, unlike in core behaviors, the engagement in low resilience behaviors, such as rubbing against an automatic brush, would be inversely related to the severity of lameness, as they are exposed to a stressor (Walker et al., 2008). The authors investigated the daily duration of brush usage and the proportion of cows in different lameness stages visiting the brush at least once per day; however, they only found a reduction in brush usage in lame and severely lame cows and only if the brush was installed away from the feed bunk (Mandel et al., 2018). In contrast, the behavioral variable for brush usage investigated in our study showed a reduction in moderately lame cows, which supports the hypothesis of Mandel et al. (2018). Furthermore, compared with nonlame cows, moderately lame cows made fewer visits to the concentrate feeder. Unrewarded visits to the concentrate feeder were found to increase waiting times and aggressive interactions at the feeder (Ketelaar-de Lauwere, 1999; Katainen et al., 2005). Consequently, moderately lame cows might avoid these situations as well as walking to and back from the feeder (Palmer et al., 2012) by reducing their number of visits. Interestingly, in comparison to nonlame cows, moderately lame cows did not have a higher probability of concentrate leftovers. This indicates that they visited the feeder sufficiently often to collect the entire daily amount of concentrate they were entitled to but avoided additional visits.

The higher milking order index in moderately lame cows showed that they were positioned further back in the milking order than nonlame cows, an observation that Main et al. (2010) made in lame and severely lame cows. This finding is possibly related to a slower walking speed in lame cows (Telezhenko and Bergsten, 2005; Chapinal et al., 2010; Beer et al., 2016), due to which these cows fall back to the end of the herd on their way to the waiting area. Additionally, moderately lame cows do not get up for milking as quickly as nonlame cows (Blackie et al., 2011a) and might not walk to the waiting area autonomously, whereas they might already be at the end of the herd when they start walking to the waiting area. Furthermore, the risk of aggressive interactions with herd mates in the waiting area might be smaller if cows position themselves rather at the end of the milking order.

The results obtained in this study are based on data of 17 farms, which were selected from 50 farms that were willing to participate. When choosing our study farms, we aimed to make a selection of farms that best matched our participation criteria and represent the variability of typical Swiss dairy farms. Although the common risk of a selection bias based on voluntary participation of the farms cannot be excluded entirely, the great variance in the prevalence of lameness in our herds indicates that the farmer's motivation for participation was based on different initial conditions. Consequently, it can be argued that our data were well balanced for the purpose of our research question.

Overall, the changes found in the lying-, activity-, and feeding behaviors, brush usage, and milking order of moderately lame cows reflect a pronounced effect of lameness on cow behavior in loose housing systems. These findings are in line with previous studies that found that lameness also affects the daily time-budget (Gomez and Cook, 2010), BCS (Walker et al., 2008), reproductive performance (Hernandez et al., 2001), and longevity (Charfeddine and Pérez-Cabal, 2017). In summary, the multifarious effects of lameness show that lame cows do not cope as successfully with their environment as nonlame cows (Galindo and Broom, 2002) and indicate an impairment of animal welfare.

The marked differences in many aspects of the behavior between moderately lame and nonlame cows are promising early indicators of lameness in dairy cows. Therefore, we see a potential to develop a suitable tool for early lameness detection based on automatic behavior recordings. However, the variability between cows was larger than the variability between farms and 
within cows, a finding that is in accordance with other studies (Kramer et al., 2009; Helmreich et al., 2014; Leiber et al., 2016). In respect to an early lameness detection system, a high variability between cows may be challenging by making it difficult to determine general threshold values. Although we found marked differences between nonlame and moderately lame cows, overlaps between these groups of cows existed. Further research should focus on whether a combination of multiple of the observed behaviors can accurately differentiate moderately lame from nonlame cows. Potentially, a system for early lameness detection will need to track changes within cows over time to achieve sufficient sensitivity and specificity.

\section{CONCLUSIONS}

The behavior of moderately lame cows was found to differ in a biologically relevant way from nonlame cows. The changes in activity, lying, and feeding behaviors (e.g., lower locomotor activity, longer lying duration, shorter eating time) are known to cause disadvantages with respect to the bodily constitution and energy supply, which may predispose moderately lame cows to other health problems and a shorter life. Moreover, the restriction in mobility is likely to further affect the cows' low resilience and social behaviors. The effects on the everyday life of moderately lame dairy cows in loose housing systems indicate that even an early stage of lameness already has a great potential effect on animal welfare.

\section{ACKNOWLEDGMENTS}

We are grateful to the farmers for their generous support of the project and to colleagues of Agroscope and the Centre for Proper Housing of Ruminants and Pigs for providing valuable expertise to our research. We further thank Dr. Andrea Fiedler (http://www .tierarzt-andrea-fiedler.de) for her efforts to teach us visual locomotion scoring in dairy cows. The project was funded by the Federal Food Safety and Veterinary Office (FSVO, Project No. 2.14.05).

\section{REFERENCES}

Alsaaod, M., C. Römer, J. Kleinmanns, K. Hendriksen, S. Rose-Meierhöfer, L. Plümer, and W. Büscher. 2012. Electronic detection of lameness in dairy cows through measuring pedometric activity and lying behavior. Appl. Anim. Behav. Sci. 142:134-141. https://doi .org/10.1016/j.applanim.2012.10.001.

Aungier, S. P. M., J. F. Roche, M. Sheehy, and M. A. Crowe. 2012 Effects of management and health on the use of activity monitoring for estrus detection in dairy cows. J. Dairy Sci. 95:2452-2466. https://doi.org/10.3168/jds.2011-4653.
Bareille, N., F. Beaudeau, S. Billon, A. Robert, and P. Faverdin. 2003. Effects of health disorders on feed intake and milk production in dairy cows. Livest. Prod. Sci. 83:53-62. https://doi.org/10.1016/ S0301-6226(03)00040-X.

Barker, Z. E., K. A. Leach, H. R. Whay, N. J. Bell, and D. C. Main. 2010. Assessment of lameness prevalence and associated risk factors in dairy herds in England and Wales. J. Dairy Sci. 93:932-941. https://doi.org/10.3168/jds.2009-2309.

Bates, D. M. Maechler, B. Bolker, and S. Walker. 2015. Fitting linear mixed-effects models using lme4. J. Stat. Softw. 67:1-48. https:// doi.org/10.18637/jss.v067.i01.

Becker, J., A. Steiner, S. Kohler, A. Koller-Bahler, M. Wüthrich, and M. Reist. 2014a. Lameness and foot lesions in Swiss dairy cows: I Prevalence. Schweiz. Arch. Tierheilkd. 156:71-78. https://doi.org/ 10.1024/0036-7281/a000553.

Becker, J., A. Steiner, S. Kohler, A. Koller-Bähler, M. Wüthrich, and M. Reist. 2014b. Lameness and foot lesions in Swiss dairy cows: II. Risk factors. Schweiz. Arch. Tierheilkd. 156:79-89. https://doi .org/10.1024/0036-7281/a000554.

Beer, G., M. Alsaaod, A. Starke, G. Schuepbach-Regula, H. Müller, P. Kohler, and A. Steiner. 2016. Use of extended characteristics of locomotion and feeding behavior for automated identification of lame dairy cows. PLoS One 11:e0155796. https://doi.org/10.1371/ journal.pone.0155796.

Bicalho, R. C., V. S. Machado, and L. S. Caixeta. 2009. Lameness in dairy cattle: A debilitating disease or a disease of debilitated cattle? A cross-sectional study of lameness prevalence and thickness of the digital cushion. J. Dairy Sci. 92:3175-3184. https://doi .org/10.3168/jds.2008-1827.

Blackie, N., J. Amory, E. Bleach, and J. Scaife. 2011a. The effect of lameness on lying behaviour of zero grazed Holstein dairy cattle. Appl. Anim. Behav. Sci. 134:85-91. https://doi.org/10.1016/j .applanim.2011.08.004

Blackie, N., E. Bleach, J. Amory, and J. Scaife. 2011b. Impact of lameness on gait characteristics and lying behaviour of zero grazed dairy cattle in early lactation. Appl. Anim. Behav. Sci. 129:67-73. https://doi.org/10.1016/j.applanim.2010.10.006.

Braun, U., L. Trösch, F. Nydegger, and M. Hässig. 2013. Evaluation of eating and rumination behaviour in cows using a noseband pressure sensor. BMC Vet. Res. 9:164. https://doi.org/10.1186/1746 $-6148-9-164$

Braun, U., S. Zürcher, and M. Hässig. 2015. Evaluation of eating and rumination behaviour in 300 cows of three different breeds using a noseband pressure sensor. BMC Vet. Res. 11:231. https://doi.org/ 10.1186/s12917-015-0549-8.

Burla, J. B., A. Ostertag, H. Schulze Westerath, and E. Hillmann. 2014. Gait determination and activity measurement in horses using an accelerometer. Comput. Electron. Agric. 102:127-133. https://doi.org/10.1016/j.compag.2014.01.001.

Burla, J. B., C. Rufener, I. Bachmann, L. Gygax, A. Patt, and E. Hillmann. 2017. Space allowance of the littered area affects lying behavior in group-housed horses. Front. Vet. Sci. 4:23. https://doi .org $/ 10.3389 /$ fvets.2017.00023.

Chapinal, N., A. M. de Passillé, J. Rushen, and S. Wagner. 2010 Automated methods for detecting lameness and measuring analgesia in dairy cattle. J. Dairy Sci. 93:2007-2013. https://doi.org/10 $.3168 /$ jds.2009-2803.

Charfeddine, N., and M. Pérez-Cabal. 2017. Effect of claw disorders on milk production, fertility, and longevity, and their economic impact in Spanish Holstein cows. J. Dairy Sci. 100:653-665. https:// doi.org/10.3168/jds.2016-11434.

Dee Whittier, W. 2008. Down cows: Potential problem for cattle producers-The Cattle Site. Accessed Mar. 30, 2017. http://www .thecattlesite.com/articles/1319/down-cows-potential-problem-for -cattle-producers/.

Deming, J. A., R. Bergeron, K. E. Leslie, and T. J. DeVries. 2013. Associations of housing, management, milking activity, and standing and lying behavior of dairy cows milked in automatic systems. J. Dairy Sci. 96:344-351. https://doi.org/10.3168/jds.2012-5985.

Dyer, R. M., N. K. Neerchal, U. Tasch, Y. Wu, P. Dyer, and P. G. Rajkondawar. 2007. Objective determination of claw pain and its 
relationship to limb locomotion score in dairy cattle. J. Dairy Sci. 90:4592-4602. https://doi.org/10.3168/jds.2007-0006.

Galindo, F., and D. M. Broom. 2002. The effects of lameness on social and individual behavior of dairy cows. J. Appl. Anim. Welf. Sci. 5:193-201. https://doi.org/10.1207/S15327604JAWS0503_03.

Gomez, A., and N. B. Cook. 2010. Time budgets of lactating dairy cattle in commercial freestall herds. J. Dairy Sci. 93:5772-5781. https://doi.org/10.3168/jds.2010-3436.

González, L. A., B. J. Tolkamp, M. P. Coffey, A. Ferret, and I. Kyriazakis. 2008. Changes in feeding behavior as possible indicators for the automatic monitoring of health disorders in dairy cows. J. Dairy Sci. 91:1017-1028. https://doi.org/10.3168/jds.2007-0530.

Green, L. E., V. J. Hedges, Y. H. Schukken, R. W. Blowey, and A J. Packington. 2002. The impact of clinical lameness on the milk yield of dairy cows. J. Dairy Sci. 85:2250-2256. https://doi.org/10 .3168/jds.S0022-0302(02)74304-X.

Gygax, L., T. Kutzer, A. Brötje, and B. Wechsler. 2015. Influence of an early exposure to the calving pen on lying behavior at calving and avoidance distance of dairy heifers. Livest. Sci. 182:108-111. https://doi.org/10.1016/j.livsci.2015.10.021.

Halekoh, U., and S. Højsgaard. 2014. A Kenward-Roger approximation and parametric bootstrap methods for tests in linear mixed models-The R package pbkrtest. J. Stat. Softw. 59:32. https://doi .org/10.18637/jss.v059.i09.

Helmreich, S., R. Hauser, T. Jungbluth, B. Wechsler, and L. Gygax. 2014. Time-budget constraints for cows with high milking frequency on farms with automatic milking systems. Livest. Sci. 167:315322. https://doi.org/10.1016/j.livsci.2014.06.014.

Hernandez, J., J. K. Shearer, and D. W. Webb. 2001. Effect of lameness on the calving-to-conception interval in dairy cows. J. Am. Vet. Med. Assoc. 218:1611-1614. https://doi.org/10.2460/javma .2001.218.1611.

Ito, K., M. A. G. von Keyserlingk, S. J. LeBlanc, and D. M. Weary. 2010. Lying behavior as an indicator of lameness in dairy cows. J. Dairy Sci. 93:3553-3560. https://doi.org/10.3168/jds.2009-2951.

Jabbar, K. A., M. F. Hansen, M. L. Smith, and L. N. Smith. 2017. Early and non-intrusive lameness detection in dairy cows using 3-dimensional video. Biosyst. Eng. 153:63-69. https://doi.org/10 .1016/j.biosystemseng.2016.09.017.

Johns, J., A. Patt, and E. Hillmann. 2015. Do bells affect behaviour and heart rate variability in grazing dairy cows? PLoS One 10:e0131632. https://doi.org/10.1371/journal.pone.0131632.

Juarez, S. T., P. H. Robinson, E. J. DePeters, and E. O. Price. 2003. Impact of lameness on behavior and productivity of lactating Holstein cows. Appl. Anim. Behav. Sci. 83:1-14. https://doi.org/10 .1016/S0168-1591(03)00107-2.

Katainen, A., M. Norring, E. Manninen, J. Laine, T. Orava, K. Kuoppala, and H. Saloniemi. 2005. Competitive behaviour of dairy cows at a concentrate self-feeder. Acta Agric. Scand. Anim. Sci. 55:98105. https://doi.org/10.1080/09064700500239453.

Ketelaar-de Lauwere, C. C. 1999. The influence of the accessibility of concentrate on the behaviour of cows milked in an automatic milking system. Neth. J. Agric. Sci. 47:1-16.

Kilgour, R. J. 2012. In pursuit of "normal": A review of the behaviour of cattle at pasture. Appl. Anim. Behav. Sci. 138:1-11. https://doi .org/10.1016/j.applanim.2011.12.002.

Kokin, E., J. Praks, I. Veermäe, V. Poikalainen, and M. Vallas. 2014. IceTag3D $^{\mathrm{TM}}$ accelerometric device in cattle lameness detection. Agron. Res. (Tartu) 12:223-230.

Kramer, E., D. Cavero, E. Stamer, and J. Krieter. 2009. Mastitis and lameness detection in dairy cows by application of fuzzy logic. Livest. Sci. 125:92-96. https://doi.org/10.1016/j.livsci.2009.02.020.

Leiber, F., M. Holinger, N. Zehner, K. Dorn, J. K. Probst, and A. Spengler Neff. 2016. Intake estimation in dairy cows fed roughage-based diets: An approach based on chewing behaviour measurements. Appl. Anim. Behav. Sci. 185:9-14. https://doi.org/10 .1016/j.applanim.2016.10.010.

Lovendahl, P., and M. G. Chagunda. 2010. On the use of physical activity monitoring for estrus detection in dairy cows. J. Dairy Sci. 93:249-259. https://doi.org/10.3168/jds.2008-1721.
Main, D. C. J., Z. E. Barker, K. A. Leach, N. J. Bell, H. R. Whay, and W. J. Browne. 2010. Sampling strategies for monitoring lameness in dairy cattle. J. Dairy Sci. 93:1970-1978. https://doi.org/10 $.3168 /$ jds.2009-2500.

Mandel, R., H. Harazy, L. Gygax, C. J. Nicol, A. Ben-David, H. R. Whay, and E. Klement. 2018. Short communication: Detection of lameness in dairy cows using a grooming device. J. Dairy Sci. 101:1511-1517. https://doi.org/10.3168/jds.2017-13207.

Nechanitzky, K., A. Starke, B. Vidondo, H. Müller, M. Reckardt, K. Friedli, and A. Steiner. 2016. Analysis of behavioral changes in dairy cows associated with claw horn lesions. J. Dairy Sci. 99:2904-2914. https://doi.org/10.3168/jds.2015-10109.

Nielsen, L. R., A. R. Pedersen, M. S. Herskin, and L. Munksgaard. 2010. Quantifying walking and standing behaviour of dairy cows using a moving average based on output from an accelerometer. Appl. Anim. Behav. Sci. 127:12-19. https://doi.org/10.1016/j .applanim.2010.08.004.

Norring, M., J. Häggman, H. Simojoki, P. Tamminen, C. Winckler, and M. Pastell. 2014. Short communication: Lameness impairs feeding behavior of dairy cows. J. Dairy Sci. 97:4317-4321. https://doi .org/10.3168/jds.2013-7512.

O'Callaghan, K. A., P. J. Cripps, D. Y. Downham, and R. D. Murray. 2003. Subjective and objective assessment of pain and discomfort due to lameness in dairy cattle. Anim. Welf. 12:605-610.

Palmer, M. A., R. Law, and N. E. O'Connell. 2012. Relationships between lameness and feeding behaviour in cubicle-housed HolsteinFriesian dairy cows. Appl. Anim. Behav. Sci. 140:121-127. https:// doi.org/10.1016/j.applanim.2012.06.005.

Phillips, C. 2002. The Welfare of Dairy Cows. Cattle Behaviour and Welfare. Second ed. Blackwell Science Ltd., Hoboken, NJ.

R Core Team. 2016. R: A language and environment for statistical computing. R Foundation for Statistical Computing, Vienna, Austria.

Roelofs, J. B., C. Krijnen, and E. van Erp-van der Kooij. 2017. The effect of housing condition on the performance of two types of activity meters to detect estrus in dairy cows. Theriogenology 93:12-15. https://doi.org/10.1016/j.theriogenology.2017.01.037.

Rutten, C. J., A. G. J. Velthuis, W. Steeneveld, and H. Hogeveen. 2013. Invited review: Sensors to support health management on dairy farms. J. Dairy Sci. 96:1928-1952. https://doi.org/10.3168/ jds.2012-6107.

Schirmann, K., N. Chapinal, D. M. Weary, W. Heuwieser, and M. A. G. von Keyserlingk. 2012. Rumination and its relationship to feeding and lying behavior in Holstein dairy cows. J. Dairy Sci. 95:3212-3217. https://doi.org/10.3168/jds.2011-4741.

Sepulveda-Varas, P., D. M. Weary, and M. A. von Keyserlingk. 2014. Lying behavior and postpartum health status in grazing dairy cows. J. Dairy Sci. 97:6334-6343. https://doi.org/10.3168/jds.2014 $-8357$.

Sogstad, A. M., O. Osteras, and T. Fjeldaas. 2006. Bovine claw and limb disorders related to reproductive performance and production diseases. J. Dairy Sci. 89:2519-2528. https://doi.org/10.3168/jds .S0022-0302(06)72327-X.

Solano, L., H. W. Barkema, E. A. Pajor, S. Mason, S. J. LeBlanc, C. G. R. Nash, D. B. Haley, D. Pellerin, J. Rushen, A. M. de Passillé, E. Vasseur, and K. Orsel. 2016. Associations between lying behavior and lameness in Canadian Holstein-Friesian cows housed in freestall barns. J. Dairy Sci. 99:2086-2101. https://doi.org/10 .3168/jds.2015-10336.

Sprecher, D. J., D. E. Hostetler, and J. B. Kaneene. 1997. A lameness scoring system that uses posture and gait to predict dairy cattle reproductive performance. Theriogenology 47:1179-1187. https:// doi.org/10.1016/S0093-691X(97)00098-8.

Telezhenko, E., and C. Bergsten. 2005. Influence of floor type on the locomotion of dairy cows. Appl. Anim. Behav. Sci. 93:183-197. https://doi.org/10.1016/j.applanim.2004.11.021.

Thomsen, P. T., L. Munksgaard, and J. T. Sørensen. 2012. Locomotion scores and lying behaviour are indicators of hoof lesions in dairy cows. Vet. J. 193:644-647. https://doi.org/10.1016/j.tvjl .2012 .06 .046 . 
Thorup, V. M., L. Munksgaard, P.-E. Robert, H. W. Erhard, P. T. Thomsen, and N. C. Friggens. 2015. Lameness detection via legmounted accelerometers on dairy cows on four commercial farms. Animal 9:1704-1712. https://doi.org/10.1017/S1751731115000890.

Thorup, V. M., B. L. Nielsen, P.-E. Robert, S. Giger-Reverdin, J. Konka, C. Michie, and N. C. Friggens. 2016. Lameness affects cow feeding but not rumination behavior as characterized from sensor data. Front. Vet. Sci. 3:37. https://doi.org/10.3389/fvets .2016.00037.

Tucker, C., D. Weary, J. Rushen, and A. M. de Passille. 2004. Designing better environments for dairy cattle to rest. Pages 39-53 in Proc. Advances in Dairy Technology - Western Canadian Dairy Seminar, Edmonton. University of Alberta, Faculty of Extension, Edmonton.

Van Hertem, T., E. Maltz, A. Antler, C. E. B. Romanini, S. Viazzi, C. Bahr, A. Schlageter-Tello, C. Lokhorst, D. Berckmans, and I. Halachmi. 2013. Lameness detection based on multivariate continuous sensing of milk yield, rumination, and neck activity. J. Dairy Sci. 96:4286-4298. https://doi.org/10.3168/jds.2012-6188.

von Keyserlingk, M. A. G., A. Barrientos, K. Ito, E. Galo, and D. M. Weary. 2012. Benchmarking cow comfort on North American freestall dairies: Lameness, leg injuries, lying time, facility design, and management for high-producing Holstein dairy cows. J. Dairy Sci. 95:7399-7408. https://doi.org/10.3168/jds.2012-5807.

Walker, S. L., R. F. Smith, J. E. Routly, D. N. Jones, M. J. Morris, and H. Dobson. 2008. Lameness, activity time-budgets, and estrus expression in dairy cattle. J. Dairy Sci. 91:4552-4559. https://doi .org/10.3168/jds.2008-1048.

Whay, H. R., D. C. J. Main, L. E. Green, and A. J. F. Webster. 2003. Assessment of the welfare of dairy cattle using animal-based measurements: direct observations and investigation of farm records. Vet. Rec. 153:197-202. https://doi.org/10.1136/vr.153.7.197.

Yu, Y., and L. Lin. 2012. Agreement: Statistical Tools for Measuring Agreement. R package version 0.8-1. http://CRAN.R-project.org/ package $=$ Agreement

Zehner, N., C. Umstätter, J. J. Niederhauser, and M. Schick. 2017. System specification and validation of a noseband pressure sensor for measurement of ruminating and eating behavior in stablefed cows. Comput. Electron. Agric. 136:31-41. https://doi.org/10 $.1016 /$ j.compag.2017.02.021. 